\title{
Creatividad en la educación universitaria. Hacia la concepción de nuevos posibles
}

\author{
Graciela Susana Pascualetto*
}

\section{Resumen / Creatividad en la educación universitaria}

La creatividad, condición muy valorizada en el siglo XX, a raíz de las profundas transformacionessociales que demandan respuestas nuevas ante los problemas emergentes e imaginación al servicio de la habitabilidad del mundo, constituye un desafío para la formación profesional. La autora efectúa un recorrido por estostópicos para centrarse luego en el proceso de transmisión y creación en la educación universitaria, analizando los niveles de la concepción desde el punto de vista pedagógico y las condiciones intersubjetivas y ambientales que favorecen la dinámica del pensamiento organizador-creador para procurar experiencias de enseñanza y aprendizaje en las que puedan germinar modos de hacer y de pensar capaces de construir nuevos posibles.

\section{Palabras clave}

aprendizaje - creación - diseño didáctico - enseñanza - ética - informacionalismo - investigación - metacognición - meta-investigación - pensamiento complejo - teorías de la creatividad.

\section{Summary / Creativity in the university education}

"Creativity", extremely valorized condition in the XX century due to the deep social transformation which demand new answers to all the emerging problems and imagination employed to the worlds ability, demands a challenge for professional formation. The author peruses over these topics to center, in the process of creation and transmition of the university education, analyzing the different conceptionslevels from a pedagogic point of view and the inter-subjective and environmental conditions which assist the organizing-creating thinking dynamic to endeavor teaching and learning experiences which are capable of giving new ways of thinking.

\section{Key words}

creation - creativity levels- complexthinking - didactic design - diverging production - ethic- infomationalism - investigation - learning - meta-cognition - meta-investigation - teaching - tranformation capacity.

\section{Resumo / Creatividade na educação universitaria}

A criatividade, condição muito valorizada no século XX, por causa das profundastransformações sociais que demandam novas respostas diante dos problemasemergentes, e a imaginação ao servico da habilidade do mundo, constitui um desafio para a formação professional. A autora, desenvolve estestópicos, para finalmente, centrar-se no processo de trasmição e criação na educação universitária, analizando osníveis da concepção, desde o ponto de vista pedagógico, e ascondiçõesintersubjetivase ambientais que favorecem a dinámica do pensamento organizador-criador para procurar experiências de ensinamento e aprendizagem, nas quais possam germinar modos de fazer e de pensar, capazes de construir novos possíveis.

\section{Palavras chave}

aprendizagem - criação - criatividade criação - desenho didáctico - ensino - ética - informacionalismo investigação - meta-cognição - meta-investigação - pensamento complexo - teorías da criatividade.

* Centro de Estudios en Diseño y Comunicación, Facultad de Diseño y Comunicación, Universidad de Palermo. infocedyc@palermo.edu

Graciela Susana Pascualetto: Licenciada en Ciencias de la Educación (U.J.F.K). Especialización en Gestión Educativa (FLACSO). Profesora de la Facultad de Diseño y Comunicación de la UP. 
Ir más allá de lo dado; generar algo nuevo, diferente. Allí radica la idea de creatividad, concepto que se desliza en los anales de la educación desde el último siglo, aunque -demás está decir- antes también se produjeron experiencias innovadoras y estimulantes del pensamiento y de la imaginación creadora.

La facultad de producir una obra original, otrora reservada a pocos elegidos que poseían un don divino o se destacaban porque sus genes eran portadores de "genialidad", fue siendo desplazada por la idea de creatividad como atributo potencial de todo ser humano dada su capacidad para producir una novedad al percibir, pensar y combinar de otra forma las múltiples variables que actúan en una situación y concebir conceptos, relaciones, diseños o sistemas que modifican o trascienden a los antiguos.

Señala Castoriadis: “...creación quiere decir posición de nuevas determinaciones - surgimiento de nuevas formas, eidé, y por ende ipso facto de nuevas leyes: las pertenecientes a esos modos de ser. En un nivel más general, la idea de creación sólo implica indeterminación en este sentido: la totalidad de lo que no está nunca tan total y exhaustivamente 'determinado ' como para excluir (hacer imposible) el surgimiento de nuevas determinaciones" (Castoriadis, 1998: 32).

A mediados del siglo XX, cuando las guerras mundiales, la manipulación de la naturaleza, la opresión de los sistemas políticos e institucionales mostraron con crudeza el desgaste y las fisuras de los sólidos mantos de la Modernidad, empezaron a producirse quiebres y nuevos giros en el pensamiento filosófico y científico hegemónico. Por esa misma época y ante las nuevas determinaciones, la innovación comenzó a ser cada vez más valorizada.

En el presente artículo nos proponemos explorar el concepto de creatividad y algunas de las formulaciones de la psicología y de la pedagogía para centrarnos luego en ciertos cambios de paradigmas y en la manera en que las nuevas condiciones del mundo convergen con los requerimientos de flexibilidad, capacidad de adaptación, versatilidad y espíritu innovador. Estas demandas - que se ponen de manifiesto en distintas esferas de la actividad humana- en el terreno educativo conmueven las formas tradicionales de transmisión y de producción de conocimiento.

En este sentido, postulamos la necesidad de redefinir el concepto de "excelencia" y de procurar, a través de las acciones de enseñanza, investigación y producción, otras formas de preguntar, hipotetizar y formular respuestas a los problemas del presente ya que el saber acumulado y las experiencias precedentes si bien proveen importantes anclajes, no bastan: es imposible desembarcar en las mismas costas, porque las costas mismas han cambiado.

Creemos que el encuadre pedagógico-didáctico en la institución universitaria tiene que proporcionar oportunidades variadas para la lectura e interpretación de la realidad, para las exploraciones novedosas, la reflexión crítica y las producciones originales promoviendo la ideación de escenarios y estrategias que permitan generar nuevas visiones del conocimiento, de su construcción y de su aplicación.

Este texto, lejos de abarcar todo lo dicho acerca de la creatividad desde distintas disciplinas y enfoques teóricos, sólo intenta un recorte y un recorrido sobre el que seguramente todavía hay mucho para pensar y construir... En la invitación a compartirlo, me gustaría abrir diálogos y plantear reflexiones a través de una breve pieza literaria que muestra cómo una lectura inusual, novedosa, de un viejo refrán conservador y gastado podría dar nacimiento a una concepción diferente del mundo y de los modos de habitarlo:

"Más vale pájaro en mano porque así queda la mano contenida, controlada por esa forma tibia que la forma a su vez, que la mantiene ocupada, unida a su correspondiente brazo, que le impide agitar los dedos como alas para reunirse con las demás, con sus compañeras manos en el aire, esas otras noventa y nueve que sólo la esperan a ella para llegar a cien volando".1

\section{Creatividad: Aproximaciones iniciales}

Crear proviene del latín "creare" que significa hacer algo nuevo, generar algo que antes no existía. En esta potencialidad radica la creatividad, "fenómeno polisémico, multidimensional y de significación plural" (Garaigordobil Landazabal, 1995: 153) cuyas conceptualizaciones son diversas como también los puntos de vista para estudiarla.

En una primera aproximación podemos definirla como la capacidad de descubrir relaciones entre objetos o acontecimientos antes no asociados o de producir la reconfiguración de situaciones, sistemas o modelos mediante nuevas combinaciones de imágenes, ideas o experiencias.

Esta capacidad se encuentra en la base del proceso de creación independientemente de la esfera en la cual se desarrolla. Es decir: se puede ser creativo en la resolución de problemas cotidianos, como en los ámbitos profesionales, artísticos, científicos, económicos o políticos pues esta facultad, necesaria para la subsistencia del sujeto y del mundo, puede activarse en cualquier situación de vida.

Las teorías de la creatividad tuvieron un fuerte impulso en las primeras décadas del siglo XX paralelamente al desarrollo de disciplinas como la Psicología, el Psicoanálisis y la Pedagogía. Por esas mismas épocas, en las naciones involucradas en las guerras mundiales y luego en la Guerra Fría, la creatividad pasó a ser muy cotizada por la necesidad de producir instrumentos y estrategias que les permitieran a los distintos países mantener o mejorar su posicionamiento político, económico, científico y tecnológico en el contexto mundial.

El mito que explica la creatividad por obra de un don divino o como manifestación de una dotación genética especial comenzó a deshacerse y a difundirse otro supuesto: la creatividad constituye una cualidad que todos los humanos poseen en algún grado y que se puede promover a través de la educación. Guilford, uno de los más importantes precursores de la investigación en esta materia, identificó algunas de las condiciones del pensamiento creativo y las agrupó en dos categorías:

- Las de producción divergente, que involucran la fluidez de ideas, la flexibilidad de pensamiento y -a diferencia del pensamiento convergente que conduce 
a soluciones únicas- la capacidad de elaborar distintas alternativas de respuestas para resolver un problema. - Las de transformación, relacionadas con la producción de formas y pautas nuevas a partir de la reorganización o reinterpretación de lo ya conocido. (Guilford, 1971:16).

Dichas características, si bien están relacionados con la inteligencia, no se confunden con ella, ya que la buena memoria yel razonamiento lógico, por ejemplo, contribuyen al buen desempeño en la resolución de problemas -como los que frecuentemente aparecen en los tests de inteligencia, pero no necesariamente se corresponden con las cualidades que distinguen al pensamiento creativo, cuyos principales factores en la formulación de Guilford y sus seguidores son los siguientes:

Fluidez de ideas: ágil asociación y generación de pensamientos ocurrentes que permiten un acercamiento a la situación-problema con riqueza de alternativas.

Flexibilidad de pensamiento: pasaje de un campo, planteamiento o línea de pensamiento a otro con más frecuencia que el pensamiento rígido, poco dispuesto a producir nuevos movimientos.

Originalidad: producción de ideas singulares, poco frecuentes, que aportan perspectivas sorprendentes por su grado de novedad y de diferenciación con las anteriores.

Capacidad de nuevas definiciones: reflexión y resignificación de ideas y experiencias mediante otros enfoques que conducen a la creación de nuevos conceptos o a la redefinición de las categorías de pensamiento ya existentes.

Sensibilidad ante los problemas: percepción de situaciones que suelen pasar inadvertidas, atención a necesidades, deficiencias, detalles o elementos inusitados desde los cuales es posible imaginar una solución novedosa.

Desde un enfoque humanista, $M$ ay considera que el acto creador se produce en el encuentro del sujeto con el mundo; es decir, con "el modelo de relaciones significativas en el que una persona existe y en cuyo diseño participa" (May, 1977: 73), destacando que las realizaciones artísticas o científicas que se pueden calificar de esta manera requieren esfuerzo, compromiso y coraje. Otros autores ponen de relieve características de personalidad como autoconfianza, amplitud de intereses, apertura ante lo nuevo, curiosidad y entusiasmo, audacia y disposición a enfrentar situaciones de riesgo, imaginación, capacidad crítica y juicio autónomo.

Según M atussek, las personalidades creativas tienen capacidad de tolerancia ante la ambigüedad y la incertidumbre; son perspicaces y perseverantes en sus convicciones, su tarea y sus metas. "La única solución posible es muchas veces la inesperada, la imprevisible. Para conseguirla, se debe poseer la capacidad de trabajar en el trapecio de lo desconocido. Quien se apresura a escoger soluciones, se evita tensiones, pero a costa de renunciar a otras soluciones mejores y más maduras" (Matussek, 1984: 28).

En cuanto a los productos creativos, Taylor los agrupa en cinco niveles según el grado de transformación que suponen. Aún a riesgo de abundar en las clasificaciones, las incluimos brevemente tomando como referencia la presentación que realiza Garaigordobil Landazabal (1995: 175-176).

Creatividad expresiva: es el nivel más elemental de creatividad y se basa en la espontaneidad, la libertad, la improvisación. Pone en juego el cuerpo, el grafismo 0 el lenguaje en realizaciones que no demandan saberes previos, técnicas o destrezas especiales.

Creatividad productiva: en este nivel se aplican técnicas adecuadas a los objetivos que se pretenden. Requiere ciertas aptitudes y habilidades para dar forma y plasmar las manifestaciones de la imaginación en realizaciones variadas de orden artístico o científico.

Creatividad inventiva: implica la producción de relacionesy/o la combinación de elementos de modos diferentes, no habituales, en realizaciones que alcanzan el nivel de descubrimientos o inventos científicos y técnicos. Éstas demandan articulaciones novedosas y formas diferentes de interpretación simbólica. Creatividad innovadora: significa la formulación de ideas nuevas y la transformación del medio a través de realizaciones con alto grado de originalidad. En este nivel es necesario un amplio conocimiento del campo en que se opera.

Creatividad emergente: es el nivel más elevado por la reestructuración que supone. Implica la formulación de ideas radicalmente nuevas y de alto grado de abstracción que se manifiestan en la filosofía, las religiones, la estética o las diversas ciencias.

Entre las condiciones que favorecen el despliegue de la creatividad, distintas investigaciones coinciden en poner de relieve la importancia del ambiente en que se desenvuelve el sujeto. Los espacios físicos ricos en estímulos y materiales propician el desarrollo del pensamiento y de la imaginación, como asimismo las relaciones sociales democráticas donde es posible explorar, experimentar, equivocarse, expresar distintos puntos de vista, cambiar de perspectiva y reformular ideas o realizaciones. Como señalan Lowenfeld y Lambert Brittain - investigadores que también ubicamos a mediados del siglo XX-, el "ambiente de vive como quieras' parece ejercer una influencia tan negativa como un medio autoritario, donde el individuo esté completamente dominado" (Lowenfeld y Lambert Brittain, 1994: 70). Así, los ámbitos insuficientemente estructurados como los excesivamente pautados son restrictivos de las experiencias creativas, aspecto de singular importancia en el terreno educativo y sobre el que volveremos más adelante.

\section{La sociedad informacional: otros procesos, otras demandas}

No es casual que las disciplinas científicas pongan énfasis en los estudios sobre la creatividad cuando el mundo comienza a manifestar cambios de gran envergadura con una velocidad que produce el envejecimiento de la experiencia y de muchos saberes acumulados por su dificultad o incapacidad para resolver las necesidades y problemas emergentes. En el siglo XX, dice Hobsbawm, a "una época de catástrofes que se extiende desde 1914 hasta el fin de la segunda guerra mundial, siguió un período de 250 
30 años de extraordinario crecimiento económico y transformación social, que probablemente transformó la sociedad humana más profundamente que cualquier otro período de duración similar".

(Hobsbawm, 1995: 15)².

Tras la reconfiguración política mundial, hacia las décadas de 1970 y 1980, se inician las reformas de los estados nacionales que, en su viraje neoliberal, producen la apertura de los mercados y promueven procesos de descentralización administrativa y de privatización de empresas y servicios antes regidos por el poder central.

Tales transformaciones cambian la racionalidad del funcionamiento social: los estados nacionales, instituciones que durante la Modernidad cumplieron una fuerte función reguladora y otorgaron fundamento a la educación, pierden peso ante la lógica cambiante e incierta de las organizaciones del mercado en las cuales la innovación, la competitividad y la rapidez se convierten en estrategias para permanecer vinculado a las redes de interconexión globalizadas.

La reestructuración capitalista está relacionada con una nueva forma de producción y desarrollo que Castells denomina "informacionalismo". Este paradigma se basa en el conocimiento como fuente principal de productividad y tiende a niveles de complejidad cada vez más elevados en el procesamiento de información y en la generación de tecnologías. Su rasgo distintivo es la interconexión en redes que transforman sustancialmente las formas de producción industrial, de comercialización y de prestación de servicios en geografías que se van configurando como espacios de flujos más que como emplazamientos estables con localización fija.

En esta transformación, la “innovación tecnológica y el cambio organizativo, centrados en la flexibilidad y la adaptabilidad, fueron absolutamente cruciales para determinar la velocidad y la eficacia de la reestructuración" (Castells, 1999: 45), requiriendo mentes innovadoras y nuevas formas de sinergia 0 articulación entre ciencia, tecnología, poder político, industria y mercado. Correlativamente, el mundo transformado demanda nuevas estrategias de habitabilidad pues ante la diversidad de situaciones sociales, la inestabilidad, que presentan y la incertidumbre que suscitan, las modalidades de vida y de trabajo forjadas por la tradición se ven conmovidas, fisuradas, volviéndose en muchos casos inadecuadas para actuar en los nuevos contextos.

Estos cambios políticos, sociales, económicos, tecnológicos y organizacionales surgidos en los países centrales, se manifiestan con diferentes rasgos según el posicionamiento de cada nación en el marco internacional y afectan de distintos modos a la población, aunque pareciera haber un denominador común: una importante brecha entre quienes permanecen conectados a la red de flujos e innovaciones y quienes quedan al margen o circulando por sus bordes asumiendo día a día el riesgo de la exclusión.

Volviendo a Castells: " ...el constante cambio de roles y situaciones en una sociedad definida por la innovación, flexibilidad e impredecibilidad en todas las esferas, requiere que la gente redefina constantemente sus roles en el trabajo, en la familia, con sus amigos. Por lo tanto, la reestructuración de la personalidad para satisfacer adecuadamente las nuevas funciones demandadas por la sociedad requiere reunir todos los nuevos códigos y mensajes desde diferentes redes relacionadas con las diversas dimensiones de la vida" (Castells, 1994: 49).

¿Es posible desarrollar la capacidad de transitar por el trapecio de lo desconocido avizorando la complejidad del horizonte y agudizando el ingenio para concebir espacios y futuros que sigan siendo habitables para los hombres y mujeres del planeta?

\section{Pensamiento complejo: Entre el conocimiento y el misterio}

Así como Castells postula el paradigma del informacionalismo para analizar los nuevos procesos sociales y tecnológicos, Morin a partir de un pensamiento transdiciplinario postula el paradigma de la complejidad para aproximarse a lo real y para entender el conocimiento como proceso multidimensional "que depende de condiciones físico-bioantropo-socio-culturo-históricas de producción y de condiciones sistémico-lingüístico-paradigmáticas de organización" sosteniendo que una epistemología compleja "debe girar alrededor del problema de la verdad pasando de perspectiva en perspectiva y, esperémoslo, de verdades parciales en verdades parciales" ...(M orin, 1988: 33- 34).

El paradigma de la complejidad implica un giro en el pensamiento filosófico y científico y en las formas de producción y transmisión. El saber acumulado por la humanidad no es definitivo, no está cerrado. Es un conjunto de certezas provisorias a partir de las cuales generar otras aperturas, indagaciones y descubrimientos que se "embuclan" en un proceso recursivo donde las incógnitas, los errores, las confusiones, las turbulencias, las intuiciones, la luminosidad y las emociones que estas búsquedas y hallazgos despiertan, constituyen la fuente que moviliza el pensamiento desde lo conocido hacia lo misterioso, desde lo enigmático hacia las nuevas concepciones y configuraciones.

El pensamiento complejo, en la perspectiva de Morin, es una actividad humana, una aventura que se despliega en los niveles conscientes e inconscientes a través de movimientos que involucran la comprensión, el razonamiento, la explicación, el mito, la magia en una dinámica de organización y creación que pone en juego distintas competencias teóricas, técnicas y prácticas.

En el pensamiento complejo concurren, interactúan, compiten, se tornan antagónicas, se complementan y colaboran operaciones múltiples y diversas que involucran -e incluso exceden- los rasgos distintivos de la creatividad antes señalados; operaciones que suponen diferentes componentes y movimientos psíquicos que van, por ejemplo, de la incertidumbre a la producción de nuevas certezas provisorias; de lo teórico a lo empírico en las hipótesis a verificar; de la sorpresa a la metáfora ante situaciones más próximas al sueño o a la poesía que a la ciencia; de la lógica 
inductiva o deductiva a la analógica en la búsqueda de otras ideas; de la comprensión intuitiva a la demostración a través de la creación de un principio explicativo; de la imagen sincrética al diseño original...

El acto organizador-creador del pensamiento genera ideas, sistemas, tecnologías y procedimientos novedosos, pero también destruye otros, con las ventajas y desventajas que toda mutación conlleva. Como sabemos, las tecnologías informacionales permiten operaciones tan disímiles como dirigir una orquesta sinfónica o conducir una guerra por control remoto y clonar una oveja o un ser humano sin saber de qué manera ese ser artificialmente engendrado experimentará la vida y llegará a la muerte.

Ante el poder y la envergadura de las realizaciones científico-técnicas actualmente posibles, Morin (1984) propone una "ciencia con conciencia" que en el orden de lo ético, como saber que atraviesa las distintas realizaciones humanas- actualiza una vez más aquella exhortación de Einstein -uno de los creadores más importantes de nuestra historia-, quien en las postrimerías de su vida dijo: "Todo hombre, tanto al levantarse como al acostarse, debe formularse la siguiente pregunta: ¿para qué hago lo que hago ${ }^{3}$, interrogante problemático que, sin dudas, permanece abierto.

\section{Transmisión y creación en la institución universitaria}

En la sociedad moderna, la misión de la Universidad fue definida como la creación y transmisión de conocimientos del más alto nivel, actuando así como una institución de excelencia donadora de sentido que establece ideales y orientaciones en diversos campos sociales, culturales, éticos, científicos y tecnológicos. Inscripta en este contexto, la formación profesional apunta al desarrollo de competencias para "saber hacer" en una trama relacionante de teorías, métodos, técnicas y habilidades prácticas fertilizadas por la imaginación creadora y la actividad reflexiva del pensamiento.

En las primeras décadas del siglo $\mathrm{XX}$, al tiempo que los estudios sobre la creatividad se profundizan y esta condición empieza a cotizarse entre los sectores gubernamentales y productivos, se ubica a la Universidad en un rol de preeminencia social. Afirmó Whitehead en 1929: “ Lo que importa para una nación es la existencia de una relación muy estrecha entre sus elementos creadores de todo tipo, de tal manera que el estudio influya el medio social y recíprocamente. Las universidades son los principales agentes de esta fusión de actividades como instrumentos eficaces de progreso. Naturalmente, no son los únicos agentes, pero es un hecho hoy en día que las naciones que progresan son también aquellas donde las universidades son florecientes" 1 .

En un siglo atravesado por profundos cambios que tornan más acuciantes las preguntas sobre el futuro, esta convicción -y el reclamo que lleva implícito- sigue presente en distintas esferas políticas, económicas y culturales que demandan a la educación universitaria nuevas formas de relación entre enseñanza, investi- gación y desarrollo para aportar, desde su lugar, a la solución de los nuevos problemas que la sociedad experimenta.

En el marco de los idearios que orientan su funcionamiento y que las hacen diferentes unas de otras, las universidades se ven en la necesidad de reconsiderar sus fundamentos, sus planes curriculares y su interacción con otras instituciones científicas, tecnológicas, culturales, empresariales, etc. para redefinir sus propuestas de enseñanza e investigación y sus aportes al desarrollo social. Como afirma Pérez Lindo: “Estamos experimentando una mutación en el modo de producir y transmitir los conocimientos. Lo cual significa que debemos revisar al mismo tiempo los modelos epistemológicos, los contenidos de las materias y los procesos de enseñanza-aprendizaje" (Pérez Lindo, 1998: 93).

En este entramado, ¿cómo pensar de nuevo el concepto de excelencia? ¿Cuáles son los conocimientos y las modalidades de producción y transmisión que la Universidad debería promover? ¿Por qué? ¿De qué maneras? Las anteriores preguntas Ilevarían a una larga y compleja discusión que excede el propósito de este artículo. No obstante, si coincidimos en que los "procesos de creación, investigación e innovación" son esenciales a la misión de las universidades para generar nuevos conocimientos y " contribuir al mejoramiento de la condición humana" (Escotet, 1996: 41), se pone de relieve la importancia de revisar las relaciones de transmisión, apropiación y concepción a través del planeamiento curricular y de las estrategias de enseñanza e investigación que se llevan a cabo.

Los conocimientos, valoraciones, prescripciones y experiencias generados por la humanidad a lo largo de los siglos constituyen la herencia que las generaciones adultas transmiten a las nuevas para propiciar la continuidad social, legándoles su significación y valor. "El sentido de una experiencia o acto cualquiera surge 'en alguna parte', 'en algún momento', como la acción consciente de un individuo para 'resolver un problema'en relación con su entorno natural o social. No obstante, puesto que la mayoría de los problemas a los que se ve enfrentado el individuo afloran a la vez en las vidas de otras personas, las soluciones a esos problemas no son sólo subjetivamente sino que también intersubjetivamente relevantes" (Berger y Luckmann, 1997: 35).

La relevancia de esta donación de sentidos, en algunos aspectos, hoy es cuestionada; con las transformaciones experimentadas por el mundo, cambiaron también los procesos de socialización y la constitución del sujeto se produce de maneras diferentes. Los modos de llegar a ser adolescente y joven están, como nunca antes, fuertemente marcados por las tecnologías de la comunicación, las estrategias de mercado y los discursos mediáticos con su multiplicidad de operaciones y su proficuidad de informaciones, ofertas y promesas. Prestar atención a las nuevas formas de subjetivación es dar lugar a los sujetos del aprendizaje "tal como son" y exige repensar la configuración de los espacios y tiempos educativos, como así también la transferencia, apropiación y producción de conocimientos. 
La transmisión a cargo de los grupos de pertenencia y de las instituciones educativas es fundamental para la inscripción de los sujetos en una genealogía, para observar las formas en que los problemas fueron intersubjetivamente abordados en el devenir histórico y para develar algunas de las razones - nadie puede abarcar ni todo el saber ni todos los sentidos- por las cuales el presente, la sociedad, la ciencia, la tecnología, el arte, la educación adoptan estas configuraciones y estilos. Así, la "transmisión- revelación" mantiene y activa la memoria permitiendo que sus contenidos salgan a luz y puedan ser objeto de interpretación, crítica y reestructuración.

Sin embargo, en este proceso tienen que autorizarse ciertas pérdidas, ciertos olvidos, ciertos grados de indeterminación para que se pueda manifestar la novedad y la diferencia en itinerarios capaces de crear nuevas formas y articulaciones. La transposición rígida de conocimientos, pautas y modelos se cierra en la circularidad y conduce a la repetición ciega en el afán de imponer a las nuevas generaciones -para las que el mundo legado siempre será viejo- copias de mapas e itinerarios prefijados. Éstos, si bien constituyen caminos orientadores y puntos de mira, necesitan también el espacio de lo desconocido y lo intrigante para que el aprendizaje movilice la imaginación y el pensamiento, la energía y la pasión en nuevos recorridos y formas de acercamiento a la realidad; en nuevas exploraciones y experiencias creativas haciendo de sí mismos y de la realidad alguna cosa diferente. Tal es la tarea a realizar por los adolescentes y los jóvenes que se están formando en esta época de tanta incertidumbre y de tantas turbulencias. $Y$ es también la tarea nada sencilla de "mediar entre lo viejo y lo nuevo" que le compete a la educación (Arendt, 1996: 205); mediación a través de la cual será posible recrear y trascender la herencia, los contenidos recibidos por transmisión y las convenciones que dieron forma al mundo e instituyeron los imaginarios, las prácticas sociales y las leyes en cuyo interior será preciso trabajar para lograr superarlas.

"Toda profesión -dice May- puede y de hecho requiere, en cierta medida, algo de valor creativo" pues en una época de transformaciones radicales hacen falta " personas de coraje capaces de apreciar y dirigir este cambio" (May, 1977: 29), necesidad que, obviamente, se hace extensiva a la formación de los profesionales que tienen frente a sí tan grande desafío.

\section{Niveles de la concepción y pedagogía universitaria}

El pensamiento complejo, en la formulación de Morin, se constituye sobre la base de aspectos físicos y culturales, subjetivos y sociales, racionales e inconscientes, heredados y construidos en sus propios movimientos. Consideramos que esta conceptualización nos puede ayudar a pensar desde el punto de vista pedagógico los procesos -también multidimensionales y complejos- de transmisión y creación en la educación universitaria.

Morin denomina concepción "al nuevo modo de organizar la experiencia y pensar lo posible" (Morin, 1988: 156) mediante el engendramiento de ideas novedosas, la formación de imágenes mentales, el diseño de imágenes materiales y la formación de conceptos combinando operaciones inteligentes e imaginación creadora.

El autor sostiene que hay distintos niveles de concepción: " el primero es el de una concepción en el seno de una teoría que permite concebir; el segundo es el de la concepción que permite concebir una teoría nueva, adecuada a los datos o a los fenómenos que exigen ser concebidos; el tercer nivel es el de la concepción de la concepción en el que se conciben y vuelven a poner en cuestión los principios organizadores de las teorías" (Morin, 1988: 203-204).

A partir de esta formulación, proponemos analizar ciertas prácticas pedagógicas en las instituciones universitarias, algunas ya instaladas y otras que merecerían mayor atención en los ámbitos de formación profesional y científica.

La concepción en el seno de una teoría se corresponde con las formas de enseñanza, investigación y producción más habituales y se apoya fundamentalmente en la transmisión y aplicación de conocimientos ya instituidos, autorizados y legitimados por la autoridad educativa. La función de transmisión puede estar a cargo de los profesores habituales de cada asignatura, de especialistas invitados, de conferencistas, como también puede ser delegada a distintos medios técnicos: libros académicos, información periodística, videos, películas, materiales que circulan por Internet... Sin embargo, la dinámica del pensamiento y de la imaginación creadora requiere espacios y tiempos de análisis, diálogo y crítica para favorecer la interpretación, valoración y jerarquización de la información con el propósito de realizar una producción innovadora, aún en el contexto de las teorías y métodos preexistentes.

La concepción de una teoría nueva -segundo niveles una tarea mucho más ardua y compleja. Históricamente, las teorías nuevas surgen cuando las existentes resultan inadecuadas para explicar la realidad y resolver problemas en su marco conceptual y metodológico. En esas circunstancias, algún individuo o algunos grupos que perciben hechos, fenómenos o acontecimientos de un modo diferente al que utilizan quienes siguen operando en el marco de una teoría determinada, observan detalles, dificultades o inconsistencias, detectan otros movimientos o dinámicas y realizan asociaciones distintas a partir de las cuales pueden redefinir o crear nuevos conceptos cuyo grado de compatibilidad con los anteriores puede ser diverso: desde una actualización de perspectivas hasta una ruptura con ellas para dar lugar a un modo totalmente diferente de comprender y explicar los hechos y fenómenos del mundo.

Estos procesos, insertos en el contexto sociohistórico, pueden ser favorecidos a través de prácticas destinadas al desarrollo de la investigación y la producción. En los ámbitos institucionales específicos -esto es, en cada una de las universidades- las formas que asuman las propuestas de enseñanza, investigación y articulación con otras organizaciones sociales, darán cuentas del empeño puesto en la creación de nuevos conceptos y teorías, para lo cual las estrategias pedagógicas 
poseen, también, un papel preponderante.

En el tercer nivel de la concepción, siguiendo con la propuesta de Morin, se sitúa la concepción y otra vuelta al cuestionamiento de los principios organizadores de la teoría concebida, con lo cual se sigue desencadenando el proceso de pensar e imaginar nuevos posibles en un recorrido no exento de errores, quiebres, complicaciones y hallazgos originales y sorprendentes que hacen repensar el conocimiento y el conocimiento que tenemos del conocimiento.

En tal sentido, la práctica de la meta-cognición y de la meta-investigación ${ }^{2}$ favorece las idas y vueltas por los conceptos, clasificaciones, principios, técnicas y procedimientos metodológicos ya construidos y por las formas de operar con ellos tanto por parte de las comunidades científico-académicas en las distintas épocas como a nivel individual y grupal en el propio proceso de concebir, apreciar la concepción, confrontarla con otras formas de pensar y diseñar, contrastarla con la realidad empírica, evaluarla, reformularla... en un devenir que favorece la conciencia del conocimiento y de la creación.

Estos procesos se desenvuelven en el tiempo y en diferentes escenarios de la cultura, la ciencia, el arte y la educación; trascienden los límites de una institución y mucho más de un aula o de un laboratorio, ya que comprometen a distintas comunidades de conocimiento y creación. No obstante, en la movilización del pensamiento y de la imaginación desde cada ámbito de enseñanza y aprendizaje, están también las posibilidades de actualizar las potencias creativas latentes en todo sujeto humano y de realizar una contribución valiosa al conocimiento público.

\section{Dinámica de los procesos de enseñanza, aprendizaje y creación}

La complejidad que asume el funcionamiento de la sociedad informacional y la producción creativa e innovadora, como así también el reto que supone para la población en general y para los profesionales, científicos y creadores de las diferentes ramas de la cultura y el arte estar integrados socialmente y mantenerse activos en los sistemas de producción e intercambio globalizados, plantea, como decíamos, la necesidad de repensar los criterios de excelencia y los postulados pedagógicos atendiendo a la complejidad de los procesos creativos para favorecerlos a través del diseño didáctico.

En las instituciones universitarias se trasmiten, cuestionan, recrean y aplican contenidos procedentes de diversas disciplinas. Éstas poseen objeto de estudio, lógica interna y métodos de producción de conocimiento particulares. M uchas veces los problemas que se estudian requieren -y es aconsejable que así seaabordajes inter o transdisciplinarios relacionando campos de estudio, metodologías y/o estrategias de intervención pues debido a su complejidad y a sus múltiples incidencias abordarlos desde una sola parcela del conocimiento o desde una perspectiva única conduce a soluciones restringidas y parciales. Por otra parte, las relaciones educativas están signadas por factores biopsíquicos y sociales como la edad, el género, la pertenencia social, los roles institucionales y los recursos personales puestos en juego; factores, todos ellos, que influyen en las situaciones de enseñanza y aprendizaje, en las motivaciones intrínsecas y en los saberes y valores que se vehiculizan.

La identidad de profesores y alumnos se edifica en su propia biografía y en ella asume un papel primordial el vínculo con los otros, su interacción con el medio externo, las experiencias de conocimiento como así también la percepción del propio yo y las formas que asume su despliegue en la confrontación con la realidad. Enseñar y aprender supone la consideración de estos factores ya que en la comunicación cada sujeto -y su peculiar historia- interactúa con otros según sus deseos o conflictos realizando intervenciones que, con sus matices singulares, van configurando las escenas educativas.

Tener en cuenta estos atravesamientos, estos cruces, como así también la singularidad de cada sujeto y la forma en que es afectado por la propuesta de enseñanza "conduce a la búsqueda de soluciones personales, a inventar procedimientos pedagógicos originales, a aplicar no ya el momento conocido, sino enfoques específicos que implican ritmos y organizaciones igualmente específicos. Contar con la complejidad -de los individuos, de las situaciones, de la organización- conduce a un funcionamiento en sistema abierto, mientras que una estructura estática y congelada oculta estas complejidades y sus especificidades" (Husti, 1992: 283).

Esta forma de funcionamiento en contextos signados por la transformación de los criterios epistemológicos, la especialización de las ciencias y las innovaciones tecnológicas demanda la diversificación de las estrategias de enseñanza, el aprovechamiento pedagógico de diversos recursos sociales y la consideración de las múltiples variables que actúan en el proceso educativo para diseñar situaciones donde, a la vez que se transmitan saberes y experiencias, se promueva el análisis contextualizado, el pensamiento crítico, la imaginación creadora y las producciones novedosas.

Las aulas, talleres, laboratorios, bibliotecas, centros de recursos e institutos de estudios universitarios constituyen esos ámbitos donde se conjugan espacios, tiempos, vínculos intersubjetivos y medios técnicos. Ámbitos que con las tecnologías de la información y la comunicación adquieren otras formas de articulación entre lo físico y lo virtual, dando lugar a escenas donde adquieren mayor relevancia las operaciones de elaboración del conocimiento, de resolución de problemas y de promoción de las potencialidades creativas.

Las situaciones son cambiantes, la realidad es incierta, las organizaciones se estructuran y reestructuran con frecuencia, las concepciones filosóficas coexistentes son plurales, las ciencias presentan múltiples modelos, los tiempos se aceleran y las distancias se reducen. La vida cotidiana y las instituciones cambian; también las culturas y los imaginarios sociales. En escenarios de esta naturaleza no hay respuestas para todo de antemano y es ese espacio de indeterminaciones el que, trayendo otra vez a Castoriadis, puede dar lugar a otras determinaciones y a otros modos de ser. 
Para los jóvenes, ciertas representaciones y valores que las generaciones adultas hemos internalizado acerca de la sociedad, la educación y el trabajo no tienen la misma significación, pues el acontecer cotidiano, el acceso al mercado laboral, los procedimientos tecnológicos y las formas de procurar el éxito en la sociedad informacional, ponen de manifiesto la ruptura y el debilitamiento de los sistemas antiguos.

Estos quiebres habilitan para la búsqueda y el hallazgo de formas de pensar y de hacer antes inimaginables pues como ya decíamos, citando a Castells, es necesario apropiarse de otros códigos y procurar nuevos modos de relación para construir y asumir los diferentes roles que el mundo actual demanda.

“Lo que está 'dado'o supuesto al comienzo de nuestra construcción no es ni la más firme realidad allí afuera ni un conocimiento a priori: es siempre otra versión construida de un mundo que hemos dado por supuesto para ciertos fines. Toda versión del mundo construida previamente puede tomarse como dada para las construcciones siguientes. Así, en efecto, la construcción de mundos implica la transformación de los mundos y las versiones del mundo ya hechas" (Bruner, 1998: 104).

La creatividad, esa forma de encuentro con la realidad capaz de modificar y generar ideas y obras originales implica una mirada diferente como así también una actitud reflexiva sobre las propias percepciones; el develamiento de ciertas representaciones que por su persistencia se toman como naturales y la disposición para reconsiderarlas a la luz de las condiciones actuales, evaluar la relación medio-fines y cambiar las viejas estrategias en función del engendramiento de nuevas realidades.

La acción creativa es anticipadora, requiere atención y disposición al riesgo para diseñar escenarios novedosos y operar en la creación de conceptos, símbolos y relaciones que implican otra formas de mirar, comprender y explicar la realidad; otra forma de configurar situaciones y de pensar alternativas de solución a las necesidades y problemas emergentes. El deseo de descubrir mueve el pensamiento y permite vislumbrar otros posibles, manteniendo la actividad a pesar de las interferencias, contradicciones o desavenencias que en ciertos momentos obstruyen este proceso.

La perspicacia en la captación de problemas, insuficiencias, necesidades, lagunas, indeterminaciones brinda indicios para imaginar y combinar de otra manera elementos, experiencias y conocimientos que por rutina se repiten como "más de lo mismo", perdiendo de vista la oportunidad que ofrecen para introducir la diferencia, la perspectiva novedosa y dar lugar a una nueva concepción. El sujeto creativo es aquel que descubre esos indicios, que percibe lo que otros no advierten y que produce un giro original en la acción y el pensamiento.

La capacidad de observación, la apreciación de las variables que conforman una situación, la selección de la información relevante y su jerarquización, como así también el juego fluido del pensamiento y la posibilidad de desplazarlo de un campo de referencia a otros, conduce al aprendizaje autónomo y al desarrollo de las potencialidades creativas en tanto fortalece la capacidad de dimensionar y evaluar una cuestión, de deconstruirla y reconstruirla en otro sentido, logrando, muchas veces ese plus que la convierte en una realización inusual, sorprendente. A la hora de abordar una situación nueva, el sujeto activa su memoria y emergen a la conciencia imágenes o ideas concebidas a lo largo de su vida en las instituciones educativas y fuera de ellas. Al analizar las circunstancias presentes, las variables que en ellas intervienen y el desafío que su resolución implica, considera la pertinencia de dichas representaciones e ideas y evalúa si se inscribe en esos marcos o si los saberes y experiencias anteriores son inadecuados en las nuevas circunstancias.

En consecuencia, la disponibilidad de conocimientos generales y contextuales sobre el mundo como también de saberes específicos sobre la disciplina facilita el reconocimiento y la delimitación de situaciones problemáticas tanto en el terreno de la realidad empírica como de la teoría, los métodos y las técnicas producidos históricamente en esos campos. No obstante, aferrarse dogmáticamente a ellos constituye un obstáculo cuando frente a lo desconocido los esquemas de pensamiento rígidos y estereotipados -es decir, los mundos viejos- turban los rasgos singulares del presente e impiden otras respuestas fuera de los marcos conocidos. Evitar la reducción de lo novedoso a lo preexistente es una de las condiciones para el desarrollo de la creatividad en las aulas y talleres universitarios.

\section{Creatividad y diseño didáctico}

"La vida del aula debe interpretarse como una red viva de intercambio, creación y transformación de significados. Los procesos de aprendizaje son, en definitiva, procesos de creación y transformación de significados. La intervención docente en el aula se encamina a orientar y preparar los intercambios entre los alumnos/as y el conocimiento, de modo que se enriquezcan y potencien los sistemas de significados compartidos que van elaborando los estudiantes" (Pérez Gomez, 1994: 99).

En esta concepción, la intervención docente tenderá al diseño de situaciones donde la propiedad organizadora y creadora del pensamiento pueda ser dinamizada por la curiosidad, el deseo, la sorpresa, el asombro... Cuando lo que antes se mantenía oculto se hace visible y enunciable, el querer aprender orienta los procesos energéticos hacia el descubrimiento, el proyecto, la realización...

Desde el punto de vista cognitivo, la producción, intercambio y transformación de significados potencia las operaciones de análisis de los factores intervinientes en cada situación, la búsqueda y procesamiento de la información, la justificación de una postura y la elaboración de estrategias que conduzcan a las mejores decisiones técnicas, estéticas, científicas y éticas. Tal proceso supone, además, la suspensión temporaria del juicio evaluador que, cuando se realiza con demasiada premura, cercena tempranamente la posibilidad de hallar respuestas más adecuadas y de mayor calidad. 
Esta red viva, que incluye también los intercambios virtuales, es el ámbito donde los encuentros intersubjetivos y el sostén que brinda el grupo puede ayudar a construir ese espacio-tiempo para aprender a manejarse en terrenos complejos y variables; en situaciones ambiguas, conflictivas 0 inciertas; en escenarios indeterminados, difusos o intrigantes para favorecer experiencias creativas y concepciones novedosas tanto en el aspecto simbólico como en el de las realizaciones materiales.

La dinámica grupal favorece el surgimiento de nuevas formas de concebir, pues facilita el juego simbólico y las actividades de simulación como también la cooperación en el flujo de ideas, la flexibilidad del pensamiento, la escucha del otro y las discusiones en torno a los temas y problemas en cuestión.

En tal sentido, diseñar situaciones que combinan el estudio individual -porque, dicho sea de paso, el aprendizaje y la potencialidad creativa es propia de cada persona- con el diálogo, el debate, la confrontación de posturas y la crítica facilita el encuentro con esas irregularidades, obstáculos e indeterminaciones que -tanto en el terreno de la realidad material como en el de las teorías- puede potenciar los descubrimientos y las articulacioneS que lleven al nacimiento de nuevas relaciones simbólicas.

Siguiendo con Pérez Gomez: «Al tomar en consideración el carácter subjetivo, cambiante y creador de las variables que configuran la vida del aula, la enseñanza no puede concebirse como una mera aplicación de normas, técnicas y recetas preestablecidas, sino como un espacio de vivencias compartidas, de búsqueda de significados, de producción de conocimiento y de experimentación en la acción». (Pérez Gomez, 1994: 100).

La cristalización de los conocimientos o el uso rutinario de las prescripciones didácticas tiende a la estereotipia de las situaciones de enseñanza y aprendizaje; limita los vínculos intersubjetivos, la afluencia de ideas, las exploraciones personales y el contacto con otras fuentes de información. Además, resulta insuficiente en "zonas indeterminadas de la práctica -tal es el caso de la incertidumbre, la singularidad y el conflicto de valores- que escapan a los cánones de la racionalidad técnica" (Schön, 1992: 20) y en circunstancias donde la dinámica del grupo no se "ajusta" a las presuposiciones o cuando una contingencia provoca movimientos no esperados desbaratando los planes previos. La reflexión permite repensar las prácticas profesionales - tanto en la docencia como en otros campos- indagando sobre la escena presente, el contexto, las necesidades y problemas para decidir otras articulaciones, otros procedimientos e "inventar" nuevas modalidades resolutivas cuya eficacia puede asimismo ser evaluada mediante la reflexión.

De esta manera, el diseño didáctico, más que una forma preconcebida con delimitaciones rígidas, es un proceso donde se pone en juego la complejidad en actividades de estudio, experimentación, investigación o simulación que enseñan a explorar, tolerar la incertidumbre y comprender que no existe una solución preestablecida ni una respuesta única incentivando la exploración de nuevos mundos, de modo tal que con la mediación de la actividad reflexiva las imágenes e ideas a concebir sean apropiadas y alcancen matices originales.

Aquí, y a pesar del difundido supuesto de que "el tiempo es oro", es preciso contemplar la complejidad de los procesos de conocimiento y creación estableciendo tiempos flexibles y heterogéneos para evitar que el oportunismo o el afán de respuestas inmediatas limiten el proceso a realizaciones chatas que estancan las potencialidades subjetivas dificultando, incluso, la valoración de las propias posibilidades y la producción de trabajos de mayor valor creativo.

Proponer y dialogar sobre diferentes modelos de interpretación y explicación de la realidad como así también de producción de objetos materiales 0 simbólicos favorece la pluralidad de ideas, la flexibilidad del pensamiento, la expresión subjetiva, el ejercicio de distintas habilidades, el despliegue de la imaginación y los saltos cualitativos que arrojan nueva luz para descubrir otros horizontes y posibilidades.

Las tareas de investigación, como parte de las actividades de desarrollo académico o en la instrumentación didáctica de una asignatura, son propicias para fomentar el pensamiento y la imaginación. Desde las incógnitas que movilizan las búsquedas, pasando por las facetas más creativas de la formulación de hipótesis, hasta el hallazgo de ciertas "verdades" (provisorias) en las diferentes indagaciones y reconsideraciones de los datos empíricos y de las categorías conceptuales es muy probable que aparezcan indicios que tornen visibles objetos 0 relaciones antes no percibidos motivando otras formas de pensamiento y, con ello, la creación de nuevos conceptos, principios o teorías.

Por otra parte, dar participación a los estudiantes en actividades de diagnóstico y en el diseño de proyectos de producción vinculados con situaciones reales de la práctica profesional en distintos contextos de actividad favorece el pensamiento anticipador, el ejercicio de estrategias de planificación, la construcción de escenarios, la formulación de hipótesis y la movilización en torno a la solución de problemas; operaciones, todas ellas, que ponen en juego la capacidad de asociación, relación y combinación de variables, como asimismo la perseverancia en la tarea y el disfrute por los logros alcanzados.

Estos procesos requieren la habilitación de los alumnos para que realicen sus propias exploraciones, para que cuestionen el saber instituido, para que disientan con los docentes; es decir, para que desplieguen su sensibilidad, su imaginación, su pasión y su pensamiento. Ello implica asumir el riesgo de la ignorancia pues no se puede prever qué rumbos tomará el pensamiento de los estudiantes y en qué medida sus propios hallazgos pueden poner en cuestión los conocimientos legitimados.

No tener respuestas preconcebidas para todo de ningún modo significa inconsistencia teórica, metodológica o práctica por parte de la docencia. Significa, más bien, reconocer al otro con sus potencialidades de pensamiento, creación y producción; aceptar que ni el más sabio puede tener siempre las soluciones 
en la mano y que nada está tan absolutamente determinado como para no admitir otros modos de ser. Creemos que ambientes de aprendizaje donde los vínculos intersubjetivos y la relación con el conocimiento contemple estas realidades, estos atravesamientos, pueden albergar la diversidad de sujetos, pensamientos, deseos y situaciones para promover el aprendizaje y favo recer realizaciones creativas capaces de hacer del mundo algo nuevo, diferente.

\section{Notas}

${ }^{1}$ Esta expresión de Whitehead es citada por Augusto Pérez Lindo (1985): Universidad, política y sociedad. Bs. As. EUDEBA.

${ }^{2}$ La Prof. María Elsa Bettendorff desarrolla este concepto en "La meta-investigación en el aula como aporte al desarrollo de competencias metodológicas y críticas". En: Procesos y Productos. Experiencias Pedagógicas en Diseño y Comunicación. XII Jornadas de Reflexión Académica. Facultad de Diseño y Comunicación de la Universidad de Palermo. Febrero, 2004.

\section{Bibliografía}

Arendt, H. (1996). Entre el pasado y el futuro. Barcelona: Península.

Berger, P. y Luckmann, T. (1997). Modernidad, pluralismo y crisis de sentido. Barcelona: Paidós.

Bruner, J. (1998), Realidad mental y mundos posibles. Barcelona: Gedisa.

Castells, M. (1999). La era de la información. Volumen I. La sociedad red. México: Siglo XXI.

Castells, M . (1994), "Flujos, redes e identidades: una teoría crítica de la sociedad informacional". En: AA VV, Nuevas perspectivas crítica en educación. Barcelona: Paidós.

Castoriadis, C, Hecho y por hacer. Pensar la imaginación (1998), Buenos Aires: Eudeba.

Escotet, M. A. (1996). La formación universitaria frente a la explosión del conocimiento", Revista de Educación Superior de la Universidad de Palermo. Año I, N1 1. Buenos Aires.

Garaigordobil Landazabal (1995), Psicología para el desarrollo de la cooperación y de la creatividad. Bilbao: Desclée De Brouwer.

Gimeno S., J. y Pérez G., A.I. (1994). Comprender y transformar la enseñanza Madrid: Morata.

Guilford, J.P. En: Strom, R.D. Comp. (1971). Creatividad y educación. Buenos Aires: Paidós.

Klimovsky, Gregorio (9-11-2003), "El aprendizaje de la ética", Revista La Nación, Buenos Aires.

Hobsbawm, Eric (1995). Historia del siglo XX. Barcelona: Crítica-Grijalbo.

Husti, Aniko, "El tiempo escolar: un prisionero del empleo del tiempo" (1992). Revista de Educación № 298. Madrid. Lowenfeld, V., Lambert Brittain, W. (1994). Desarrollo de la capacidad creadora. Buenos Aires: Kapelusz.

Matussek, P.(1984). La Creatividad desde una perspectiva psicodinámica. Barcelona,: Herder.

May, R. (1977), La valentía de crear. Buenos Aires: Emecé Morin, E.. (1988) El método. El conocimiento del conocimiento. Madrid :Cátedra.

Morin, E. (1984). Ciencia con conciencia. Barcelona: Anthropos.

Pérez Lindo, A. (1985). Universidad, política y sociedad. Buenos Aires: Eudeba.

Pérez Lindo, A. (1998). Nuevos paradigmas y cambios en la conciencia histórica. Buenos Aires: Eudeba.
Schön, D.(1992). La formación de profesionales reflexivos Barcelona: Paidós.

Universidad de Palermo. Facultad de Diseño y Comunicación (2004). Procesos y Productos. Experiencias Pedagógicas en Diseño y Comunicación. XII Jornadas de Reflexión Académica en Diseño y Comunicación. Buenos Aires. 